\title{
LOW FREQUENCY WAVE RESONANCE IN FRINGING REEF ENVIRONMENTS
}

\author{
Andrew WM Pomeroy ${ }^{123}$, Ap Van Dongeren ${ }^{2}$, Ryan J Lowe ${ }^{1}$, \\ Jaap SM van Thiel de Vries ${ }^{23}$, Jan Roelvink ${ }^{234}$
}

\begin{abstract}
Low frequency wave resonance has been postulated to enhance damage to coral reef protected coastlines during storm events. This paper uses the numerical model XBeach to examine the dynamics that contribute to resonance that have been previously observed on a fringing reef on Guam during tropical storm Man-Yi (Péquignet et al., 2009). The methods to identify resonance in numerical (or field data) are comprehensively reviewed with three indicators of resonance proposed based upon data obtained at two locations in the model domain: 1 . The water surface elevation must be highly coherent, 2 . The phase difference must (closely) correspond to $0^{\circ}$ or $180^{\circ}$, and 3 . Amplification of the signal must be observed between the reef crest and the shoreline. XBeach simulations demonstrated that resonance could be reproduced under 'normal' wave conditions, but only when bottom friction was minimal and hence values that were atypically low for coral reefs. However, under tropical storm Man-Yi conditions, resonance was reproduced with reasonable bottom friction values. A sensitivity analysis demonstrated that, although the frequency associated with resonance was not affected by the choice of bottom friction coefficients, the magnitude of the amplification was significantly affected. Ongoing research is being undertaken to investigate the resonant response for a wider variety of reef morphologies and incident wave forcing conditions.
\end{abstract}

Keywords: low-frequency waves; coral reefs; fringing reefs; resonance

\section{INTRODUCTION}

Low-frequency wave resonance has been intensively studied in coastal systems and has been shown to be an important physical and engineering design consideration in harbors (e.g. Harkins and Briggs, 1995; Miles, 1974; Okihiro et al., 1993; Wu and Liu, 1990) on beaches (e.g. Karunarathna et al., 2005; Özkan-Haller et al., 2001; Suhayda, 1974) as well as in the laboratory (e.g. Kirby et al., 2006). It has been postulated that for coastal environments characterized by fringing reefs, resonant low frequency wave oscillations may be responsible for coastal damage observed during typhoons (Nakaza and Hino, 1991) or tropical storms (Péquignet et al., 2009). However, few reef studies (e.g. Lugo-Fernández et al., 1998; Péquignet et al., 2009) have recorded resonant oscillations in the field, with the most convincing study being that on Guam during tropical storm Man-Yi (Péquignet et al., 2009).

Laboratory and numerical studies have demonstrated that low frequency wave resonance may occur in nearshore environments that are characterized by certain natural frequencies set by the morphology (such as for a coral reef with a long horizontal bottom)(Nakaza and Hino, 1991; Nwogu and Demirbilek, 2010). In these studies, the promotion of resonance has been suggested to be due to the interaction of these natural frequencies with oscillations generated by the time varying contributions of the wave group forcing. Consistent observations were made in the analysis of data obtained during tropical storm Man-Yi by Péquignet et al. (2009) who concluded that a combination of the water depth, the time scale of forcing by the wave groups and the ability for low-frequency waves to reflect at the shoreline, defined the capability for resonance to occur.

Fringing reef environments are typically characterized by steep fore-reef slopes $(<1: 15)$ that rise from deep water to shallow reef crests $(\sim 0.5-2 \mathrm{~m})$ and reef flats, which connect directly, or via a shallow lagoon, to the shoreline. Incident wave motions are mostly dissipated on the fore-reef and reef crest and, as consequence of this process, only low frequency motions or minimal incident wave motions are generally able to persist across the reef flat (e.g. Brander et al., 2004; Hardy and Young, 1996; Young, 1989). In addition to shallow water depths, high roughness in the form of coral canopies of various coral species may significantly dissipate incident wave energy (e.g. Lowe et al., 2005c; Monismith, 2007; Pomeroy et al., submitted). This very large bottom roughness distinguishes these environments from e.g. sandy beaches or harbors.

In this paper we present the preliminary results of a study that investigates low frequency resonance in fringing reef environments. We review the observations obtained on Guam (Péquignet et al., 2009) with the assistance of the numerical model XBeach (Roelvink et al., 2009) and initially consider the resonance response to both 'normal' and extreme (Man-Yi) wave cases for different bed

\footnotetext{
${ }^{1}$ The University of Western Australia, School of Earth and Environment and The UWA Oceans Institute, 35 Stirling Highway, Crawley, Western Australia, 6009, Australia

${ }^{2}$ Deltares, Department ZKS and HYE, P.O. Box 177, 2600 MH, Delft, The Netherlands

${ }^{3}$ Delft University of Technology, Faculty of Civil Engineering and Geosciences, Section Hydraulic Engineering,

P.O. Box 5048, $2600 \mathrm{GA}$, Delft, The Netherlands

${ }^{4}$ UNESCO-IHE, P.O. Box 3015, 2601 DA, Delft, Netherlands
} 
friction parameters. We then consider how different fringing reef morphological parameters (reef width, depth and friction) more broadly affect the generation of resonance in fringing reef systems.

\section{METHODS}

\section{Guam Model}

XBeach was used to model the hydrodynamic processes on an idealized fringing reef (Ipan) at Guam. The analysis was based upon a simplified reef morphology (Fig. 1) and incident wave conditions observed prior to and during the tropical storm Man-Yi (Péquignet et al., 2009). At this site, the forereef slope rises at $\sim 1: 11$ from a depth of $-20 \mathrm{~m}$ to a shallow reef flat depth of $-0.5 \mathrm{~m}$, which extends $450 \mathrm{~m}$ to the steep shoreline. The estimated wave friction factor associated with the short waves (ie. frequencies $0.05-0.20 \mathrm{~Hz}$ ) on the forereef is $f_{w}=0.4 \pm 0.1$ and on the reef flat is $f_{w}=0.12 \pm 0.04$ (Péquignet et al., 2011) in which the variation in the coefficient reflects the spatial variability of the roughness length across the reef. The forereef wave friction factor is approximately consistent with the value determined to calibrate the incident wave dissipation in a numerical model of Ningaloo Reef (Van Dongeren et al., 2012). These values were then used to estimate the short wave bottom friction dissipation rate as (e.g. Jonsson, 1966):

$$
D_{f}=\frac{2}{3} \rho \pi f_{w}\left(\frac{\pi H}{T_{m 01} \sin k h}\right)^{3}
$$

where $T_{m 01}$ is the mean period defined by the first- and zeroth moments of the wave spectrum, $h$ is the water depth and $H$ is the instantaneous root-mean-squared wave height. An estimate of an equivalent low frequency frictional parameter $\left(f_{c}\right)$ was not reported by Péquignet et al. (2009). Point data $(x$ and $y)$ used for the analysis of low frequency wave resonance was obtained from the model at locations equivalent to those in the field and cited in Péquignet et al. (2009).

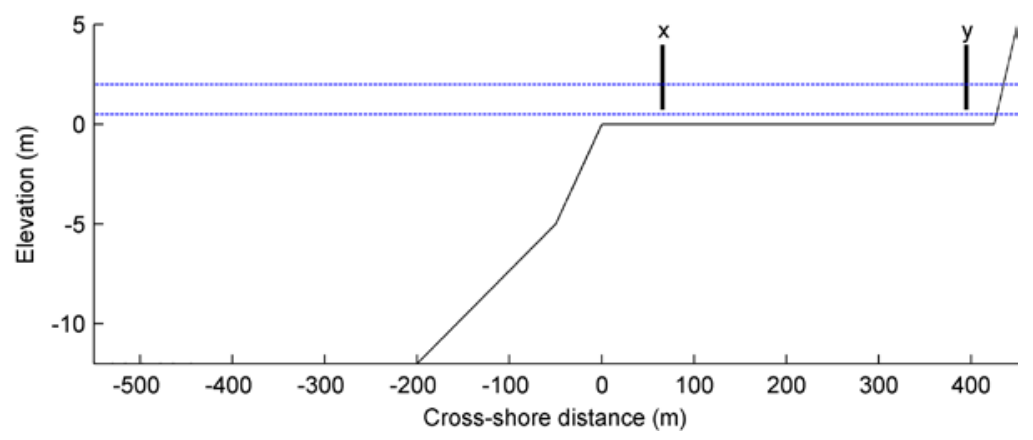

Figure 1. Guam reef morphology based upon Péquignet et al. (2009). The vertical lines denoted by $x$ and $y$ indicates the points from which data was obtained from the model for analysis. The lower water depth represents 'normal' conditions whilst the larger water depth occurred during tropical storm Man-Yi.

Six hydrodynamic simulations (Table 1) were defined to capture the 'normal' and storm conditions observed at Guam but with three different frictional coefficients on the reef flat (no friction, $f_{c}=0.05$ and $f_{c}=0.1$ ). The range of values considered captures frictional coefficient estimated for a variety of reefs (e.g. Lowe et al., 2005a; Lowe et al., 2005b; Rosman and Hench, 2011; Van Dongeren et al., 2012). The hydrodynamic simulations produced a stationary time series of data suitable in duration to obtain the frequency resolution required for analysis of the low-frequency waves. The offshore boundary was driven by a JONSWAP spectrum.

\begin{tabular}{|c|c|c|c|c|}
\hline Case & $\begin{array}{l}H_{m 0} \\
(\mathrm{~m})\end{array}$ & $\begin{array}{c}T_{p} \\
(\mathrm{~s})\end{array}$ & $\begin{array}{c}h_{r} \\
(\mathrm{~m})\end{array}$ & $\begin{array}{l}f_{c} \\
(-)\end{array}$ \\
\hline Normal (No Friction) & \multirow{3}{*}{1.0} & \multirow{3}{*}{9.5} & \multirow{3}{*}{0.5} & 0.00 \\
\hline Normal (Low Friction) & & & & 0.05 \\
\hline Normal (High Friction) & & & & 0.10 \\
\hline Man-Yi (No Friction) & \multirow{3}{*}{4.0} & \multirow{3}{*}{12.0} & \multirow{3}{*}{2.0} & 0.00 \\
\hline Man-Yi (Low Friction & & & & 0.05 \\
\hline Man-Yi (High Friction) & & & & 0.10 \\
\hline
\end{tabular}


Using the proposed resonance indicators (outlined below), the amplification, coherence and phasespectra were evaluated for each simulation. The spectral components of the analysis were assessed by use of the Welch's averaged modified periodogram method with Hanning windows (50\% overlap), which yield a spectral bandwidth of $\sim 0.00049 \mathrm{~Hz}$. The identified resonant frequencies were compared to the ‘open basin' analytical estimate (Wilson, 1966),

$$
T_{n}=\frac{4 L}{(2 n+1) \sqrt{g h}} \quad n=0,1,2 \ldots
$$

which was calculated with Eq. 2 for the still water conditions plus/minus the standard deviation of the water depth variation in the model simulations. This produced a confidence band centered on the estimated frequency. Here $L$ is the width of the reef flat, $h$ is the water depth on the reef, $g$ is the gravitational acceleration and $n$ is the resonant mode being considered (the number of nodes in the resonant waveform). Eq. (2) has been previously found to provide good agreement with the time scale of resonant motions observed in reef field studies (Lugo-Fernández et al., 1998; Péquignet et al., 2009).

\section{Fringing reef sensitivity analysis}

A multivariate sensitivity analysis was conducted to evaluate the influence of the reef width, depth and frictional parameters on low frequency wave resonance generated on the fringing reef; the influence of a deeper lagoon was thus not considered. For the present study, the range of values simulated (Table 2) were defined to capture the variety of reef geometries observed in the field along with three friction conditions. Consistent with the models of Guam (above), the hydrodynamic simulations $\left(H_{m 0}=1.0 \mathrm{~m}\right.$, $T_{p}=9.5 \mathrm{~s}$ ) were subjected to the same data analysis procedure. Milder hydrodynamic conditions were implemented to determine if a reef could resonate under 'normal' wave conditions.

\begin{tabular}{|l|c|c|c|}
\hline \multicolumn{4}{|c|}{ Table 2. Sensitivity study simulation cases } \\
\hline & Min & Step & Max \\
\hline Reef width $\left(w_{r}\right)$ & 100 & 50 & 500 \\
\hline Reef depth $\left(h_{r}\right)$ & -1.0 & -1.0 & -2.0 \\
\hline Friction $\left(f_{c}\right)$ & 0 & 0.05 & 0.1 \\
\hline
\end{tabular}

\section{Indicators of resonance}

Three indicators were used to identify resonance from data obtained at the two spatially lagged locations $(x$ and $y$ ) within the numerical model domain. Individually, each indicator is insufficient to demonstrate the existence of resonance, as each indicator quantifies a specific characteristic of a resonant waveform. All indicators must therefore be satisfied in order to demonstrate resonance. In this manuscript we have erred on the side of more detail to provide a coherent and complete description of the methodology adopted. Such techniques have also previously been used to evaluate standing waves on beaches (e.g. Guza and Thornton, 1985).

\section{Indicator 1: A highly coherent variation in water surface elevation}

Highly coherent surface motions characterize a standing wave across a basin at the standing wave frequency in which the wave oscillates about defined nodal and anti-nodal points. In this state, the variance in surface elevation at one location is (reasonably) predictable (subject to a time lag) from the surface motion at another.

The (squared) coherence function (Bendat and Piersol, 1993) was used to identify and quantify the coherence between the signals obtained at $x$ and $y$ :

$$
\gamma_{x y}^{2}(f)=\frac{\left|G_{x y}(f)\right|^{2}}{G_{x x}(f) G_{y y}(f)}
$$

$x$ and $y$ are timeseries obtained at two spatially separated points, $\mathrm{G}_{\mathrm{xx}}(\mathrm{f})$ and $\mathrm{G}_{\mathrm{yy}}(\mathrm{f})$ are the auto-spectra of the two data sets while $G_{x y}(f)$ is the cross-spectra of the two data sets. When the (squared) coherence $\left(\gamma^{2}\right)$ is one, the signals are said to have a direct relationship (informally: one signal can be directly predicted from the other). In practice, it is not expected that a coherence of one will be achieved due to 
losses associated with reflection, signal noise and waveform changes (e.g., dissipation) as the wave propagates over the reef bathymetry. A high coherence at a particular frequency does not in itself indicate the presence of a standing wave in the data. This is because any wave form that propagates across a basin and maintains a (reasonably) consistent form will have a high coherence. An assessment of the phase relationship between the two signals is therefore required to determine if the wave is standing or progressive in character. If the signals are not coherent (correlated) than the phase relationship determined in Indicator 2 cannot be evaluated.

\section{Indicator 2: Phase difference must closely correspond to $0^{\circ}$ or $180^{\circ}$}

The oscillation of a resonant waveform around nodal and antinodal points results in a reasonably constant phase relationship between two points on this waveform. In contrast, a progressive waveform demonstrates a phase relationship that consistently varies with time (i.e. phase ramps). The phase relationship between $x$ and $y$ was determined by analysis of the coincident (Eq. 5) and quadrature (Eq. 6) components of the cross-spectra (Eq. 4) of the two signals:

$$
\begin{aligned}
& G_{x y}(\tau)=2 \int_{-\infty}^{\infty} R_{x y}(\tau) e^{-j 2 \pi f \tau} d f \\
&=C_{x y}(f)-j Q_{x y}(f) \\
& C_{x y}(f)=2 \int_{-\infty}^{\infty} R_{x y}(\tau) \cos (2 \pi f \tau) d \tau \\
& Q_{x y}(f)=2 \int_{-\infty}^{\infty} R_{x y}(\tau) \sin (2 \pi f \tau) d \tau \\
&\left|G_{x y}(f)\right|=\sqrt{C_{x y}{ }^{2}+Q_{x y}^{2}} \\
& \theta_{x y}(f)=\tan ^{-1}\left[\frac{Q_{x y}(f)}{C_{x y}(f)}\right]
\end{aligned}
$$

where $x$ and $y$ are timeseries obtained at two spatially separated lagged $(\tau)$ points, $\mathrm{G}_{\mathrm{xy}}(\tau)$ is the crossspectra of the time-series, which is determined from the cross-correlation function $R_{x y}(\tau)$ of the two timeseries. $C_{x y}(f)$ is the coincident spectrum and $Q_{x y}(f)$ is the quadrature spectrum. $\theta_{x y}(f)$ is the phase difference between the two timeseries.

In some cases the co-spectrum and quad-spectrum components are normalized by the amplitude of the cross-spectrum (Eq. 7) and are presented independently rather than combined into a phase spectrum (Eq. 8). This can be helpful when the signals being evaluated are located such that resonance will be clearly indicated by a $0^{\circ}$ or $180^{\circ}$ difference in phase, which is clearly established by the coincident spectrum alternating between +1 and -1 whilst the quadrature spectrum remains near zero. The position of the instruments, relative to the nodes associated with the standing wave harmonic considered will determine the expected phase relationship. In this study we use data at the near extremities of the fringing reef platform such that the expected phase relationship is near $0^{\circ}$ or near $180^{\circ}$.

\section{Indicator 3: Amplification of the wave signal}

For resonance to occur, amplification in the signal must exist between the two points considered. We recognize that this definition is true for systems that are not critically or over damped (e.g. Naess, 2007), which otherwise may result in a rapid reduction in the oscillatory motion such that amplification is not observed. In the context of the present discussion, we limit the analysis to cases where resonance induces an increase in wave heights. Whilst indicators 1 and 2 distinguish whether a standing wave form is present at a specific frequency, they do not provide any information about whether this wave is amplified near the coastline as would be expected for a resonating wave. This condition is readily satisfied on sandy beaches or in a port due to relatively low bed friction, however for coral reef environments, coral induced friction has been identified to play a significant role in the dissipation of wave energy (both at high frequencies and infragravity frequencies) (e.g. Lowe et al., 2005c; Pomeroy et al., submitted; Van Dongeren et al., submitted). 
In this study, the amplification was determined from the division of the energy spectrum near the shoreline by the energy spectra near the reef crest (Eq. 9). Calculation of the amplification across all frequencies produces an amplification curve. Values greater than one indicate resonance and values lower than one indicate dampened resonance (where dissipation is greater than amplification).

$$
A=\frac{S_{\text {shore }}}{S_{\text {crest }}}
$$

$S_{\text {shore }}$ and $S_{\text {crest }}$ are the energy auto-spectra near shoreline and reef crest respectively.

\section{Resonance Forcing}

To evaluate the relationship between the offshore forcing and resonant motion on the reef flat, an energy transfer function $\mathrm{H}_{e y}(f)$ between the offshore wave envelope and the nearshore spectrum was also evaluated (e.g. Emery and Thomson, 2001; Péquignet et al., 2009) for each simulation case:

$$
\mathrm{H}_{e y}(f)=\frac{\left|G_{e y}(f)\right|}{G_{e e}(f)}
$$

where $G_{e y}(f)$ is the cross-spectrum between the offshore wave envelope and the nearshore (at $y$ ) signals. $G_{e e}(f)$ is the autospectrum of the offshore wave envelope signal.

\section{RESULTS}

\section{Guam conditions}

When the Guam model was subjected to 'normal' conditions (Cases 1-3), resonance was observed only for the frictionless case $\left(f_{c}=0\right)$. For this case, distinct amplification peaks (Fig. 2a) for the first three modes of resonance were located at frequencies within the predicted analytical bands from Eq. (1) (Table 3). The phase relationship between the data obtained at the extremities of the reef flat are near $0^{\circ}$ for the first and third resonance peak, and near $180^{\circ}$ for the second resonance peak (Fig. 2b). The coherence is high (>0.9) for all three peaks observed (Fig. 2c). On the basis of the resonance indicators defined by the methodology of this study, these peaks represent resonant motions.

The results are dramatically different when bottom friction is included. Whilst small peaks can be observed at the predicted resonant frequencies for the lower friction case (Fig. 2a), these peaks are below the amplification threshold $(A<1)$. For the higher frictional case, the amplification curve flattens such that no peaks are observed. The phase relationship and the coherence for both simulations are consistent with resonant conditions (phase: $0^{\circ}$ and $180^{\circ}$, coherence: $>0.9$ ). Based upon the resonance criteria in this study, resonance was not observed.

The Man-Yi storm models (Cases 4 to 6 ) were characterized by increased mean water depth due to wave setup, larger waves offshore and a slightly longer wave period. Non-frictional resonance peaks continued to be observed in the model (Fig. 2e); however in contrast to the 'normal' conditions, resonance peaks were also observed for the low and high friction cases. The amplification represented by each peak decreased as the mode of resonance and the frictional coefficient increased (Fig. 2e). The phase relationships oscillate between $0^{\circ}$ and $180^{\circ}$ (Fig. 2f) and the coherence is high (Fig. 2g). Energy transfer peaks are located at frequencies consistent with the predicted resonant frequencies determined for each group of simulations (Fig. 2dc). The peaks diminish as the $f_{c}$ is increased in each model simulation with a greater reduction observed for the 'normal' conditions than for the storm conditions.

\begin{tabular}{|c|c|c|c|}
\hline \multicolumn{2}{|c|}{ Table 3. First three resonant frequencies for the two cases considered. } \\
\hline $\begin{array}{c}\text { Simulation Case } \\
\text { and Resonant Mode }\end{array}$ & $\begin{array}{c}\text { Lower Estimate } \\
(\mathrm{Hz})\end{array}$ & $\begin{array}{c}\text { Analytical Estimate } \\
(\mathrm{Hz})\end{array}$ & $\begin{array}{c}\text { Upper Estimate } \\
(\mathrm{Hz})\end{array}$ \\
\hline Normal (Mode 1) & 0.0013 & 0.0014 & 0.0014 \\
\hline Normal (Mode 2) & 0.0040 & 0.0042 & 0.0043 \\
\hline Normal (Mode 3) & 0.0068 & 0.0069 & 0.0070 \\
\hline & & & 0.0028 \\
\hline Man-Yi (Mode 1) & 0.0025 & 0.0026 & 0.0082 \\
\hline Man-Yi (Mode 2) & 0.0075 & 0.0078 & 0.0137 \\
\hline Man-Yi (Mode 3) & 0.0125 & 0.0130 & \\
\hline
\end{tabular}



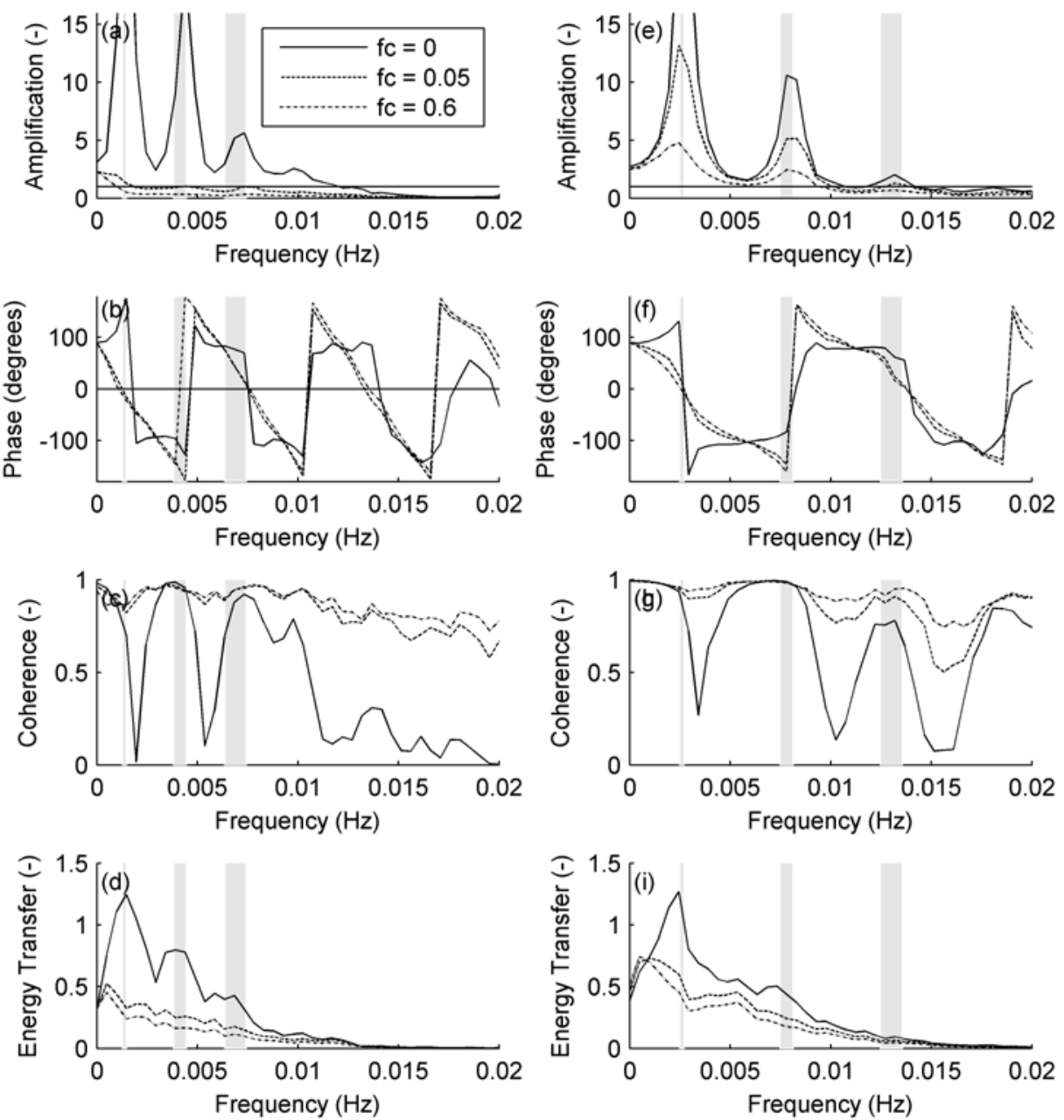

Figure 2. The left panels are for the simulations conducted under 'normal' conditions and the right panels are for the simulations conducted under the tropical storm Man-Yi conditions. (a,e) Amplification peaks for the simulation cases with different frictional coefficients $(b, f)$ The phase relationship between instrument $x$ and $y$ $(c, g)$ The coherence between the signals at $x$ and $y$. (d,i) Energy transfer between the wave group signal offshore and the nearshore signal. The shaded bands in all plots represent the analytical resonant frequency estimate and span the mean water depth plus/minus the standard deviation in the water depth obtained from the model simulations.

\section{RESONANCE SENSITIVITY ANALYSIS}

The amplification peaks for each sensitivity simulation were identified and are presented as reef width versus frequency curves for different bottom friction values (Fig. 3). For fringing reefs with a $1 \mathrm{~m}$ water depth (Fig. 3a), the resonant frequencies were not significantly affected by the frictional coefficients. The fundamental resonant motion was associated with sub-infragravity frequencies, while higher modes were associated with the, generally more energetic, infragravity motions. The gap in the data is a consequence of no second resonant mode amplification peak when the width of the reef was $300 \mathrm{~m}$. An increase in the water depth resulted in higher resonant frequencies, particularly for resonant modes 1 and 2 (Fig. 3b). 

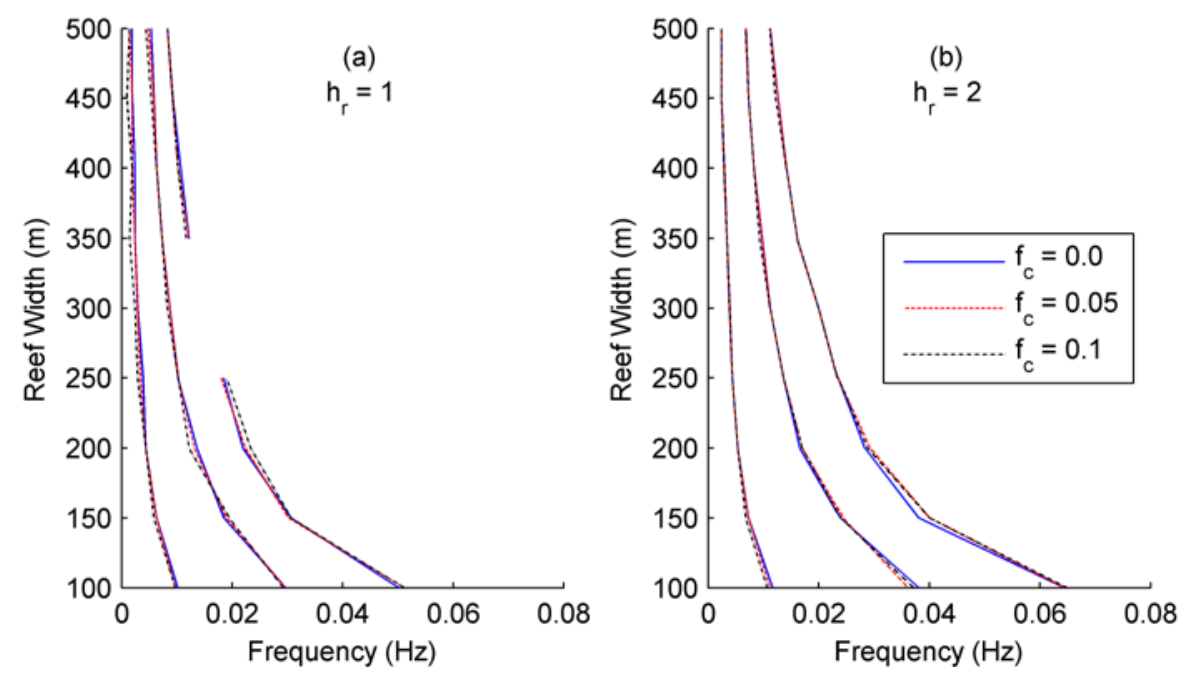

Figure 3. Frequency of the amplification peaks of the first three modes of resonance for different morphologies and friction conditions at (a) $1 \mathrm{~m}$ water depth ('normal' conditions) and at (b) $2 \mathrm{~m}$ water depth (storm conditions).

Whilst the resonance frequency was not found to be affected by the presence of friction, the magnitude of the amplification varied across the simulation cases. For the lower water level, the nonfriction amplification peaks were greatest for the fundamental resonance mode but, in general, decreased for higher modes of resonance (Fig. 4a). Wider reefs experienced greater amplification than narrower reefs. Implementation of friction into the model decreased the magnitude of the amplification peaks for all three modes. In the low friction case (Fig. 4b), the amplification of the fundamental mode decreased as the width of the reef increased. The higher modes were affected to a lesser extent. For the high friction case (Fig. 4c), low amplification peaks were observed for all three modes of resonance.
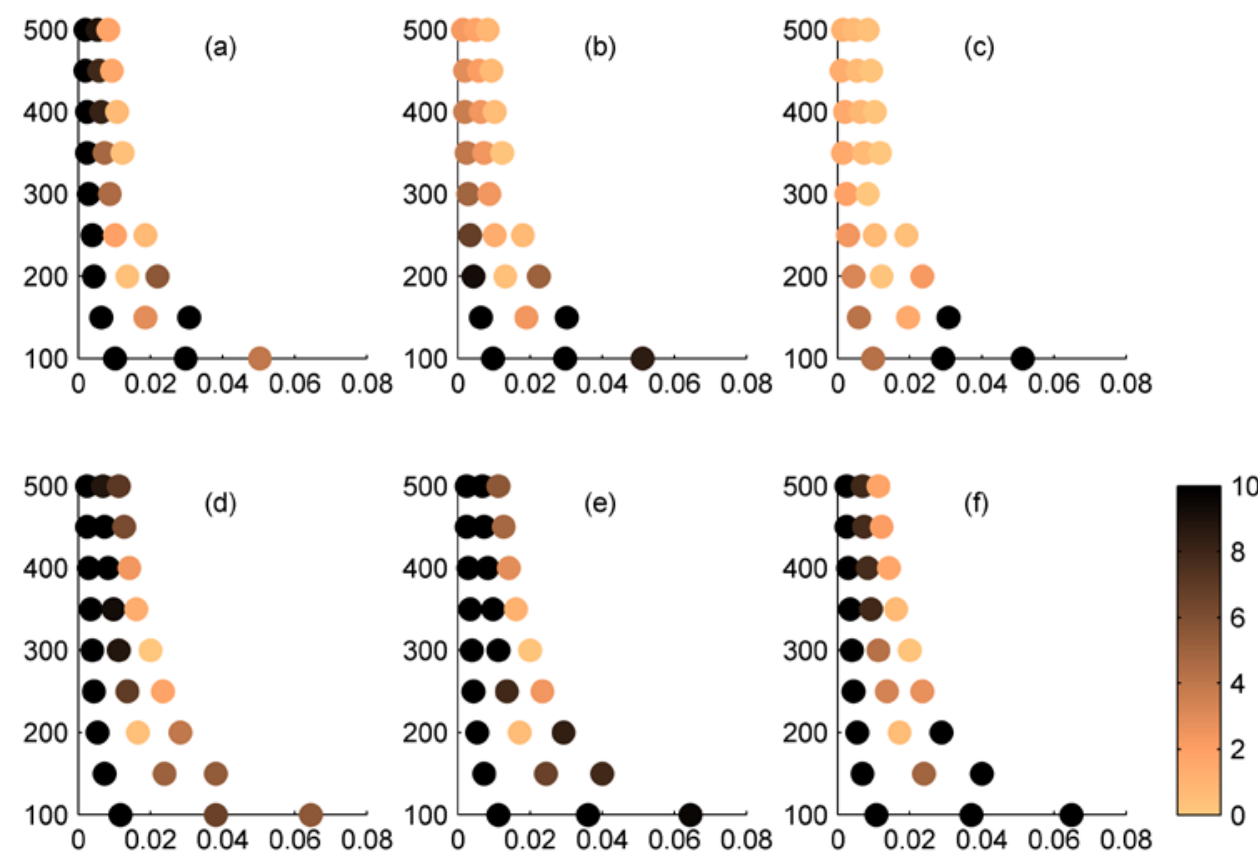

Figure 4. Magnitude of the amplification peaks for the low water (top row) and high water (bottom row) cases considered in the sensitivity study. (a,d) No friction models, $(\mathrm{b}, \mathrm{e}) f_{c}=0.05$ and $(\mathrm{c}, \mathrm{f}) \boldsymbol{f}_{c}=\mathbf{0 . 1}$. The color bar indicates the magnitude of the amplification peaks. 
When the water depth over the reef flat was increased, the amplification peaks were higher for all simulation cases considered (compare Fig. 4a-c to Fig. 4d-f). The amplification of the fundamental mode remained consistently higher for all high water frictional cases, while the second and third resonance modes decreased in amplification as the reef width narrowed but increased again for very narrow reef widths.

\section{DISCUSSION}

\section{Interpretation of Guam observations}

The presence of resonant wave motions at Guam during tropical storm Man-Yi but not during 'normal' wave conditions was found in this study to be associated with two separate physical properties: (1) an increase in the water depth over the reef during the storm event (consistent with the findings by Péquignet et al. (2009)) and (2) the frictional characteristics of the reef flat.

Higher water depths over the reef flat during the storm event increased the natural resonant frequency of the Guam fringing reef system, which was also observed in the analysis of the field data (Péquignet et al., 2009). Whilst energy was transferred from offshore wave groups to the on-reef motions for both 'normal' and storm conditions, the increased natural resonant frequency under storm conditions resulted in the resonant modes being within the more energetic infragravity frequency range. This permitted greater energy transfer to the on-reef motions. A recent study of infragravity motions at Ningaloo Reef (Pomeroy et al., submitted; Van Dongeren et al., submitted) has suggested that a large proportion of the motion on a reef is dominated by infragravity motions. This is consistent with conclusion by Péquignet et al. (2009) that forcing by infragravity waves is an important contributor to fringing reef resonance.

In addition, we found that the increased friction on the reef flat counteracted the excitation of the resonant frequencies. While it is recognized that for a coral reef that neglecting friction is not realistic, it highlights the importance that dissipation by bottom friction has on the resonant motions. The energy transfer between the offshore wave groups and the resonant motions on the reef flat was also reduced significantly. Implementation of friction for the 'normal' wave case does not change the resonance frequency however it does reduce the model amplification peaks and demonstrates that frictional damping of the incident and reflected waves impedes resonance. This is despite the observation that there is some forcing that is acting to excite the resonant frequencies. It is unclear how efficient the excitation of resonance modes by higher forcing frequencies is, however rapid dissipation of the peaks when friction is implemented suggests that this processes is relatively inefficient. For the Guam model under storm conditions, the presence of amplification peaks with the introduction of friction suggests that when the forcing frequency is close to the resonance frequency the excitation is much more efficient. This demonstrates that the increase in the resonant frequencies enables greater excitation of the resonance mode by reef flat infragravity motions, which can overcome the dissipation effects of the high rates of bottom friction dissipation. Whilst a reduction in the energy transfer was also observed for the storm cases with friction implemented, this reduction was less than that observed for the 'normal' cases and is also a reduction within a more energetic part of the spectrum. Higher amplification of the wider reefs in the sensitivity analysis is consistent with the natural frequency of these basins approaching the frequencies of the offshore wave envelope. The increase in the amplitude of the resonance peaks for narrower reefs are due to these reefs possessing resonant frequencies within the incident wave band.

\section{CONCLUSION}

This study demonstrated that resonant conditions could be generated for a variety of reef morphologies and frictional characteristics. Under 'normal' conditions, resonance was only observed at Guam for a non-frictional morphology; however for storm conditions, resonance was observed for all cases considered, including frictional cases. The sensitivity analysis provided further insight into variation of the amplification with the morphology of the reef and the choice of frictional parameter did not have a significant effect on the frequency that that was excited on the reef flat. This study suggests that the ability of a fringing reef to resonate is, in the first instance reliant on a forcing frequency on the reef flat being closely matched to a natural resonant frequency and secondly that the frictional characteristics of the reef are matched of exceeded by the forcing frequency to enable resonant motions to be excited and amplified. 


\section{ACKNOWLEDGMENTS}

Funding for this project was provided by the Deltares Strategic Research Project 1202362 (System Tools) to AVD and AWP. Additional funding was provided by the European Commission Erasmus Mundus Program to AWP, the Robert and Maude Gledden Postgraduate Research Award to AWP and a CSIRO Flagship Collaboration Fund award to RJL and AVD.

\section{REFERENCES}

Bendat, J. S., and A. G. Piersol (1993), Engineering applications of correlation and spectral analysis, J. Wiley.

Brander, R. W., P. S. Kench, and D. Hart (2004), Spatial and temporal variations in wave characteristics across a reef platform, Warraber Island, Torres Strait, Australia, Marine Geology, 207, 169-184.

Emery, W. J., and R. E. Thomson (2001), Data analysis methods in physical oceanography, Elsevier Science.

Guza, R. T., and E. B. Thornton (1985), Observations of Surf Beat, Journal of Geophysical Research, 90(C2), 3161-3172.

Hardy, T. A., and I. R. Young (1996), Field study of wave attenuation on an offshore coral reef, $J$. Geophys. Res., 101, 14311-14326.

Harkins, G. S., and M. J. Briggs (1995), Resonant forcing of harbors by infragravity waves, paper presented at Proceedings of the 24th International Conference on Coastal Engineering. Part 1 (of 3), October 23, 1994 - October 28, 1994, ASCE, Kobe, Jpn.

Jonsson, I. (1966), Wave boundary layers and friction factors, paper presented at International Conference on Coastal Engineering, ASCE, Tokyo, Japan.

Karunarathna, H., A. Chadwick, and J. Lawrence (2005), Numerical experiments of swash oscillations on steep and gentle beaches, Coastal Eng, 52(Compendex), 497-511.

Kirby, J. T., H. T. Özkan-Haller, and M. C. Haller (2006), Seiching in a large wave flume, paper presented at Coastal Engineering, World Scientific, San Diego, California.

Lowe, R. J., J. R. Koseff, and S. G. Monismith (2005a), Oscillatory flow through submerged canopies: 2. Canopy mass transfer, J. Geophys., 110, 1-14.

Lowe, R. J., J. Koseff, and S. G. Monismith (2005b), Oscillatory flow through submerged canopies: 1. Velocity structure, J. Geophys. Res, 110, 1-17.

Lowe, R. J., J. L. Falter, M. D. Bandet, G. Pawlak, M. J. Atkinson, S. G. Monismith, and J. R. Koseff (2005c), Spectral wave dissipation over a barrier reef, J. Geophys. Res., 110, C04001.

Lugo-Fernández, A., H. H. Roberts, W. J. Wiseman Jr, and B. L. Carter (1998), Water level and currents of tidal and infragravity periods at Tague Reef, St. Croix (USVI), Coral Reefs, 17, 343349.

Miles, J. W. (1974), Harbor Seiching, Ann. Rev. Fluid. Mech., 6, 17-33.

Monismith, S. G. (2007), Hydrodynamics of Coral Reefs, Ann. Rev. Fluid. Mech., 39, 35-55.

Naess, A. (2007), An introduction to random vibrations, edited, Norwegian University of Science and Technology, Trondheim.

Nakaza, E., and M. Hino (1991), Bore-like surf beat in a reef zone caused by wave groups of incident short period waves, Fluid Dyn Res, 7, 89-100.

Nwogu, O., and Z. Demirbilek (2010), Infragravity Wave Motions and Runup over Shallow Fringing Reefs, J Waterw Port C-ASCE, 136, 295-305.

Okihiro, M., R. T. Guza, and R. J. Seymour (1993), Excitation of Seiche Observed in a Small Harbor, J. Geophys. Res., 98, 18201-18211.

Özkan-Haller, H. T., C. Vidal, I. J. Losada, R. Medina, and M. A. Losada (2001), Standing edge waves on a pocket beach, J. Geophys. Res., 106, 16981-16996.

Péquignet, A. C., J. M. Becker, M. A. Merrifield, and J. Aucan (2009), Forcing of resonant modes on a fringing reef during tropical storm Man-Yi, Geophys. Res. Lett., 36, L03607.

Péquignet, A. C., J. Becker, M. Merrifield, and S. Boc (2011), The dissipation of wind wave energy across a fringing reef at Ipan, Guam, Coral Reefs, 1-12.

Pomeroy, A. W. M., R. J. Lowe, G. Symonds, A. Van Dongeren, and C. Moore (submitted), The dynamics of infragravity wave transformation over a fringing reef.

Roelvink, D., A. Reniers, A. van Dongeren, J. van Thiel de Vries, R. McCall, and J. Lescinski (2009), Modelling storm impacts on beaches, dunes and barrier islands, Coastal Eng, 56, 1133-1152.

Rosman, J. H., and J. L. Hench (2011), A framework for understanding drag parameterizations for coral reefs, J. Geophys. Res., 116(C8), C08025. 
Suhayda, J. N. (1974), Standing Waves on Beaches, J. Geophys. Res., 79, 3065-3071.

Van Dongeren, A., R. J. Lowe, A. W. M. Pomeroy, D. M. Trang, J. A. Roelvink , R. Ranasinghe, and G. Symonds (2012), Modelling infragravity waves and currents across a fringing reef, paper presented at International Coastal Engineering Conference, Santander, Spain.

Van Dongeren, A., R. J. Lowe, A. W. M. Pomeroy, D. M. Trang, J. A. Roelvink, G. Symonds, and R. Ranasinghe (submitted), Numerical modelling of low-frequency wave dynamics over a fringing coral reef.

Wilson, B. W. (1966), The Encyclopedia of Oceanography, edited by R. W. Fairbridge, pp. 804 - 817, Reinhold Pub. Co.

Wu, J.-K., and P. L.-F. Liu (1990), Harbour excitations by incident wave groups, J Fluid Mech, 217, 595-613.

Young, I. R. (1989), Wave Transformation Over Coral Reefs, J. Geophys. Res., 94, 9779-9789. 